\title{
Determinants of under-five mortality in the high mortality regions of Ethiopia: mixed- effect logistic regression analysis
}

\author{
Misganaw Gebrie Worku ${ }^{1 *} \mathbb{D}$, Achamyeleh Birhanu Teshale ${ }^{2}$ and Getayeneh Antehunegn Tesema²
}

\begin{abstract}
Background: Even though the global under-five mortality rate substantially decreased over time, Sub-Saharan African (SSA) countries including Ethiopia continue to share the huge burden of under-five mortality. Ethiopia showed a substantial reduction in under-five mortality over time but the rate of reduction has varied across regions. Therefore, this study aimed to investigate determinants of under-five mortality in the high mortality regions of Ethiopia.

Methods: A secondary data analysis was done based on the 2016 Ethiopian Demographic and Health Survey (EDHS) data. A total weighted sample of 3446 live births were included for this study. For the determinants of under-five mortality, mixed-effect logistic regression was fitted. The Intra-Class Correlation Coefficient (ICC), and Median Odds Ratio (MOR) were done to assess the presence of a significant clustering effect. The standard binary logistic regression and the mixed-effect logistic regression model were fitted and deviance $(-2 \mathrm{LL})$ was used for model comparison as the models were nested models. Variables with a $p$-value less than 0.2 in the bi-variable mixed-effect binary logistic regression analysis were considered for the multivariable analysis. In the multivariable mixed-effect logistic regression analysis, the Adjusted Odds Ratio (AOR) with the 95\% Confidence Interval (Cl) were reported to declare the statistical significance and strength of association of under-five mortality and the determinant factors.
\end{abstract}

Results: Overall, the under-five mortality rate in the high mortality regions of Ethiopia was 74 per 1000 live births and it was highest among twin births (262 per 1000 live births). In the multivariable mixed-effect logistic regression analysis, being having 6 and above births ( $A O R=3.66,95 \% \mathrm{Cl}: 1.55,8.67)$, preceding birth interval of $2-3$ years ( $A O R=0.57,95 \%$ $\mathrm{Cl}: 0.41,0.81)$ and above 3 years ( $\mathrm{AOR}=0.35,95 \% \mathrm{Cl}: 0.22,0.55)$, being twin $(\mathrm{AOR}=5.12,95 \% \mathrm{Cl}: 2.28,11.46)$, and being having antenatal care (ANC) visit during pregnancy (AOR $=0.27,95 \% \mathrm{Cl}: 0.16,0.45)$ were significant determinants of under-five mortality.

Conclusion: In this study, under-five mortality rate was highest in high mortality regions of Ethiopia. Parity, ANC visit, preceding birth interval, and multiple births were significant predictors of under-five mortality. Therefore, public health interventions that increase maternal health service utilization such as ANC and family planning service utilization to increase birth interval are needed to reduce under-five mortality among these regions of Ethiopia.

Keywords: Ethiopia, Under-five mortality, Mixed-effect analysis

\footnotetext{
*Correspondence: misgeb2008@gmail.com

'Department of Human Anatomy, College of Medicine and Health Science,

School of Medicine, University of Gondar, Gondar, Ethiopia

Full list of author information is available at the end of the article
}

\section{$\triangle B M C$}

(c) The Author(s). 2021 Open Access This article is licensed under a Creative Commons Attribution 4.0 International License, which permits use, sharing, adaptation, distribution and reproduction in any medium or format, as long as you give appropriate credit to the original author(s) and the source, provide a link to the Creative Commons licence, and indicate if changes were made. The images or other third party material in this article are included in the article's Creative Commons licence, unless indicated otherwise in a credit line to the material. If material is not included in the article's Creative Commons licence and your intended use is not permitted by statutory regulation or exceeds the permitted use, you will need to obtain permission directly from the copyright holder. To view a copy of this licence, visit http://creativecommons.org/licenses/by/4.0/ The Creative Commons Public Domain Dedication waiver (http://creativecommons.org/publicdomain/zero/1.0/) applies to the data made available in this article, unless otherwise stated in a credit line to the data. 


\section{Background}

Under-five mortality is the death of a child before reaching the age of 5 years [1]. The first 5 years of life are the most crucial years for the physical and intellectual development of children [1].

Even though there is a worldwide decrement in underfive mortality, from 5.9 million deaths in 2015 to 5.3 million in 2018, still there is a high mortality rate in African countries (81 per 1000 live births) including Ethiopia, which is around 7 times higher than in the European region [1, 2]. In Africa, under-five mortality contributes for $14 \%$ of the global burden of child mortality and in sub-Saharan Africa, it accounts for nearly $50 \%$ of child mortality, while it accounts for just $11 \%$ of the world's population [3]. Sub-Saharan Africa countries had the highest under-five mortality with 1 child in every 13 live birth dying before 5 years of age, which is 15 times higher than in high-income countries and half of all these deaths in 2018 occurred in five countries; India, Nigeria, Pakistan, Ethiopia, and the Democratic Republic of the Congo [3, 4].

Under-five child mortality in Ethiopia is one of the biggest and most difficult problems that should be given emphasis [4]. Millennium development goal (MDG) 4 was aimed at reducing under-five mortality by twothirds and this was unfinished agenda for most of the middle and lower-income countries [5]. With the current rates of child mortality in Ethiopia achieving the sustainable development goal (SDG), which is reducing under-five mortality to 55 deaths per 1000 live births by 2030 is difficult and studies revealed that there is a significant regional variation in under-five mortality [4].

That is, in some regions of Ethiopia, under-five mortality is still devastating and according to the 2016 Ethiopian Demographic and Health Survey (EDHS) report, under-five mortality per 1000 live birth in afar, Benishangul-Gumuz, and Somali were 125, 98, and 94, respectively [6].

Evidence from different literature showed that low level of maternal education, unsafe drinking water and sanitation, low family income, birth interval, short breastfeeding time, and place of delivery are among the determinants of under-five mortality [4, 7-19].

Even though Ethiopia is working on the reduction of under-five mortality, through improving coverage, quality and use of skilled care, essential newborn care, and management of preterm and low birth weight, still it is very high in the regions of Afar, Somalia, and Benishangul-Gumuz [5]. Therefore, this study aimed to explore the determinants of under-five mortality in these high-risk regions of Ethiopia. This study might give insight for health professionals, policymakers, and the community in general for appropriate intervention to reduce under-five mortality.

\section{Methods}

\section{Data source}

Secondary data analysis was conducted based on the EDHS 2016, which is the fourth survey conducted nationally from January 18 to June 27, 2016. The EDHS employed a two-stage stratified sampling technique to select respondents. In the first stage, 645 enumeration areas (EAs) (202 in urban areas and 443 in rural areas) were selected. In the second stage, a fixed number of 28 households per cluster was selected, with an equal probability systematic selection from the newly created household list. The detailed sampling procedure was presented in the full EDHS 2016 report [6].

Afar, Somali, and Benishangul-Gumuz regions were selected since based on the 2016 EDHS report, these regions had the highest rates of under-five mortality. A total weighted sample of 3446 women with a live birth in the 5 years preceding the survey were included for this study. For women who had two or more live births in the 5 years preceding the survey, the last birth was taken (Fig. 1).

\section{Study variables}

The outcome variable was the death of under-five children, which is a dichotomous variable coded as " 0 " if the child is alive and " 1 " if the child is died.

The independent variables were: proximal factors (sex of a child and multiple births), intermediate factors (mother's level of education, birth order, preceding birth interval, parity, ANC visit, respondent current age, and place of delivery), and distant factors (household wealth index, source of drinking water, sex of household head, place of residency, and presence of toilet facility) (Table 1).

\section{Data management and analysis}

Stata 14 software was used for extracting, recoding, and analysis of data. The data were weighted using sampling weight, primary sampling unit, and strata before any statistical analysis to restore the representativeness of the data and to get a reliable estimate and standard error. Descriptive statistics were done using frequencies and percentages. The EDHS data has a hierarchical structure; this violates the independent assumptions of a standard logistic regression model. Therefore, to assess the determinant factors, the mixed-effects logistic regression model with the Generalized Linear Mixed Model (GLMM) framework was used.

$$
\begin{aligned}
\log [\pi \mathrm{ij} /(1-\pi \mathrm{ij})]= & \beta 0+\beta 1 \mathrm{X} 2 \mathrm{ij}+\beta 2 \times 3 \mathrm{ij}+\beta 3 \mathrm{X} 2 \mathrm{ij} \\
& +\cdots+\beta n X n i j+\cup 0 \mathrm{i}+\epsilon \mathrm{ij}
\end{aligned}
$$

$\pi \mathrm{ij}=$ is probability of under-five mortality 


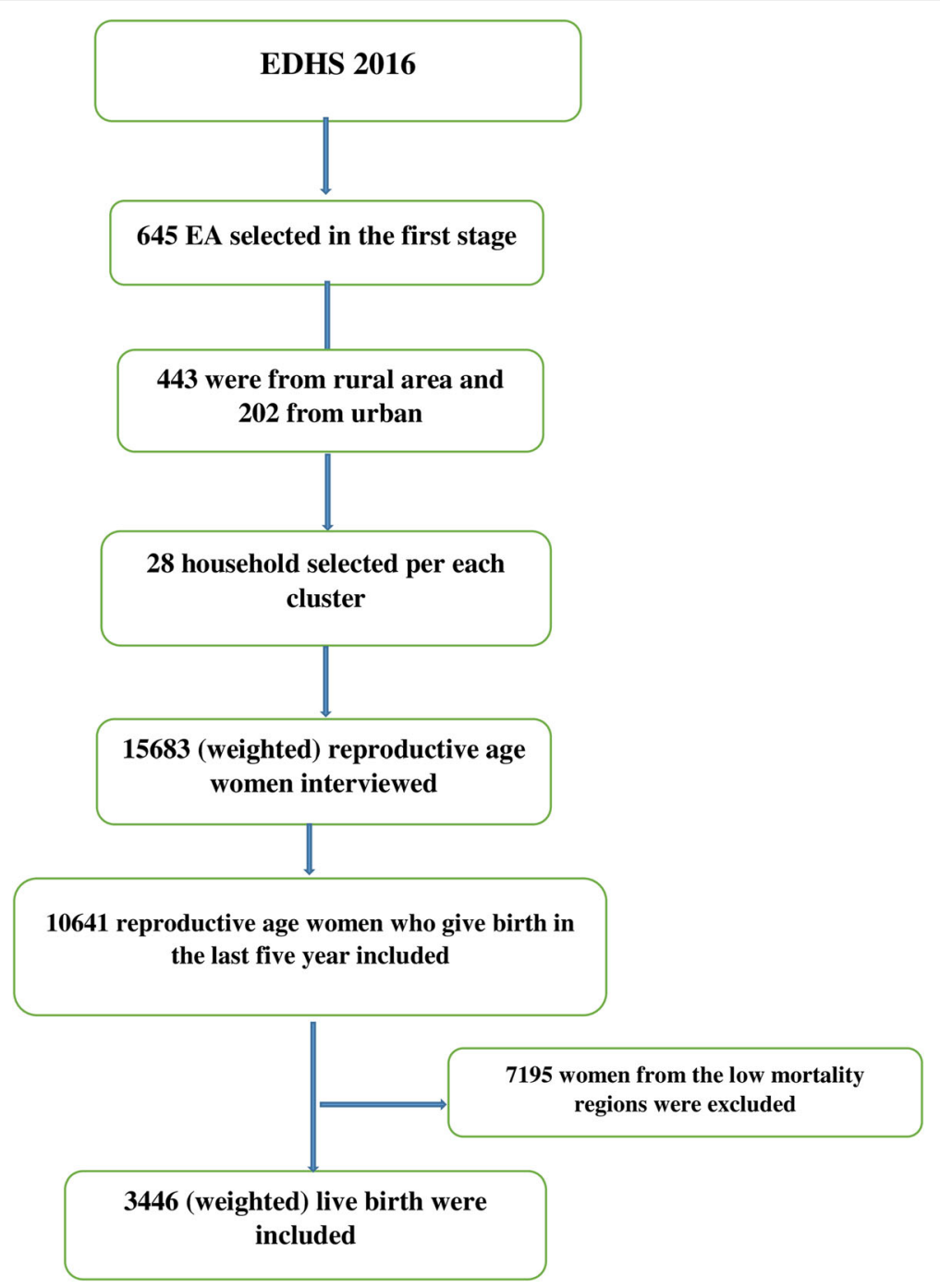

Fig. 1 Flow diagram showing the sampling

$1-\pi i j=$ is probability of surviving in the first 5 years of birth

$\beta 0=$ is $\log$ odds of the fixed intercept

$\mathrm{X} 1 \mathrm{ij} \ldots \mathrm{Xnij}=$ are independent variables of individuals and community's level

$\beta 1 \ldots \beta n$ are effect sizes of individual levels and community-level coefficients

$\mathrm{uOj}$ are random errors at cluster level

єij random error at individual level estimated by $\pi^{2} / 3$

Multicollinearity between independent variables was assessed using Variance Inflation Factor (VIF) and each of the independent variables and the mean VIF was less than 5. Intraclass Correlation Coefficient (ICC) and Median Odds Ratio (MOR) were checked to assess whether there was clustering and deviance was used for model comparison. Both bivariable and multivariable mixedeffect logistic regression were done. At the bivariable analysis variables with a $p$-value $<$ of 0.2 were considered for multivariable analysis and variables with a $P$-value of $<0.05$ in the multivariable analysis were considered as determinants of under-five mortality.

\section{Results}

Sociodemographic characteristics of study participants

A total weighted sample of 3446 was included in this study. A majority (80.9\%) of the mothers were without formal education. Approximately, $87 \%$ of study participants were from rural areas and $43.67 \%$ were from the Somali region. Most (85.95\%) of respondents were followers of the Muslim religion. About $19.38 \%$ of respondents were from households with safe drinking water supplies and the majority (58.5\%) of participants were from households with no toilet facility. Concerning wealth status, $76 \%$ of respondents were from households 
Table 1 Description and measurement of independent variables

\begin{tabular}{|c|c|}
\hline \multicolumn{2}{|c|}{ Independent variables and their description/categorization } \\
\hline Respondent age & $\begin{array}{l}\text { Current age of the mother and re-coded in to two categories with values of " } 0 \text { " for }<20 \text {, "1" for } 20-24 \text {, "2" for } 25-29 \text {, " } 3 \text { " for 30- } \\
36 \text { and " } 4 \text { " for } \geq 35 \text { years. }\end{array}$ \\
\hline Religion & $\begin{array}{l}\text { Religion of the mother that is re-coded in to three categories, "0" for Muslim, "1" for Orthodox and "2" for other religious groups } \\
\text { (combining protestant, catholic, traditional, and the other religious categories). }\end{array}$ \\
\hline Wealth status & $\begin{array}{l}\text { It is the household wealth status and in the EDHS data it was created using principal components analysis and coded as } \\
\text { "poorest", "poorer", "middle", "richer", and "richest". For this study, we recoded it in to three categories as "poor" (includes the } \\
\text { poorest and the poorer categories), "middle", and "rich" (includes the richer and the richest categories) }\end{array}$ \\
\hline Parity & $\begin{array}{l}\text { It is the total number of children a women had and re-coded in to three categories with a value of " } 0 \text { " for } 1-3 \text {, "1" for } 4-6 \text {, and } \\
\text { " } 2 \text { " for }>6 \text { children. }\end{array}$ \\
\hline Birth order & $\begin{array}{l}\text { Recoded in to four categories with a value of " } 0 \text { " for first birth order and "1" for } 2-3 \text { rd order, " } 2 \text { " for 4-5th, and " } 3 \text { " for 6th and } \\
\text { above birth order. }\end{array}$ \\
\hline Toilet facility & $\begin{array}{l}\text { The variable type of toilet facility is recoded as "0" for pit latrine (flush to piped sewer system, flush to septic tank, flush to pit } \\
\text { latrine, flush, don't know where, ventilated improved pit latrine, pit latrine with slab, and pit latrine without slab/open pit), and } \\
\text { "1" for no pit toilet latrine (no facility/bush/field, composting toilet, and others) }\end{array}$ \\
\hline Educational status & $\begin{array}{l}\text { This is the minimum educational level the mother achieved and coded in to two groups with a value of "0" for no education } \\
\text { and "1" for primary education and above. }\end{array}$ \\
\hline Sex of household & The variable sex of household head was corded as male and female in the dataset and we used without change. \\
\hline Water source & $\begin{array}{l}\text { Recoded in to two categories with value of "0" for "pipe (piped into dwelling, piped to yard/plot, piped to neighbor, and public } \\
\text { tap/standpipe) and" "1" for other source of water. }\end{array}$ \\
\hline $\begin{array}{l}\text { Preceding birth } \\
\text { interval }\end{array}$ & $\begin{array}{l}\text { The variable preceding birth interval is recoded as " } 0 \text { " for preceding birth interval of } \leq 2 \text { years, " } 1 \text { " for preceding birth interval of } \\
2-3 \text { years, and " } 2 \text { " for preceding birth interval of }>3 \text { years. }\end{array}$ \\
\hline Place of delivery & The variable place of delivery was recoded as " 0 " for home delivery and " 1 " for delivery in the health facility. \\
\hline Sex of child & The sex of the child recoded as " 1 " for male and " 2 " for female in the EDHS and used without recoding. \\
\hline Birth type & The variable birth type was recoded in to two categories as " 0 " for single birth and "1" for multiple birth. \\
\hline ANC visit & $\begin{array}{l}\text { The variable ANC visit was recoded in to two categories, "0" for woman who had no any ANC visit during their pregnancy and } \\
\text { "1" for woman who had at least one ANC visit during their pregnancy. }\end{array}$ \\
\hline Place residence & The variable place of residence was corded as rural and urban in the dataset and used without change for this study. \\
\hline Region & The variable region was coded in to 11 categories in the dataset and we used the three (Afar, Somali, and Beni shangul). \\
\hline
\end{tabular}

with a poor wealth status. Most $(82.3 \%)$ of mothers gave their birth at home and $70.3 \%$ of mothers did not have ANC visit during their last pregnancy. Regarding birth order, $30 \%$ of mothers had a birth order greater than six and $41 \%$ of mothers gave birth with a preceding birth interval less than 2 years. Moreover, $52.3 \%$ of children were males and the great majority $(98.8 \%)$ were singletons (Table 2).

\section{Prevalence of under-five mortality in the high-risks region of Ethiopia}

Two hundred fifty-seven children (7.46, 95\%CI; 6.6, $8.3 \%$ ) died before 5 years of age from total live birth with a mortality rate of 74 per 1000 live births. Among mothers with no ANC visit during their last pregnancy, there is higher under-five mortality (95 deaths per 1000 live births) relative to mothers with ANC visits (26 death per 1000 live birth). In multiple births, the rate of under-five mortality was higher (27 deaths per 1000 live births) than in singletons (8 deaths per 1000 live births). The under-five mortality rate is also differed with wealth status, falling from 80 deaths to 53 deaths per 1000 live births in poor vs rich households. In rural and urban areas, the under-five mortality rate was 78 and 47 deaths per 1000 live births, respectively. In households with untreated water sources, the under-five mortality rate was higher (78 deaths per 1000 live births) than in those with a safe water source (60 deaths per 1000). Among households with no standard toilet facility, under-five mortality was higher (79 deaths per 1000 live births) compared to those with a standard toilet facility (67 deaths per 1000 live births) (Table 3).

\section{Determinants of under-five mortality in the high-risks region of Ethiopia Model comparison/random effect analysis} Log-likelihood Ratio (LLR) test and deviance were checked, and the mixed effect logistic regression model was chosen since it had the smallest value of deviance. Furthermore, the ICC value was 0.14 and this revealed about $14 \%$ of the variability of under-five mortality was attributed due to the difference between communities/ clusters. The median odds ratio was 1.49 , indicating that if we randomly select one child from a higher-risk 
Table 2 Descriptive characteristics of the respondents in Ethiopia, $2016(N=3446)$

Variable

Regions

Afar

Somali

Benishangul-gumuz

Respondent current age

$<20$

20-24

25-29

30-34

$\geq 35$

Religion

Muslim

Orthodox

Others

Wealth index

poor

Middle

Rich

Residence

Urban

Rural

Source water

Pipe

Other

Toilet facility

Yes

No

Sex of household

Male

Female

Mother education

No education

Primary and above

Birth order

$1 s t$

2-3

4-5

6 and above

Parity

1-3

4-6

$>6$

Preceding birth interval

$\leq 2$ years weighted frequency (\%)

$1062(30.8 \%)$

$1505(43.6 \%)$

879 (25.5\%)

$154(4.5 \%)$

$793(23 \%)$

$1025(29.7 \%)$

706 (20.5\%)

$768(22.3 \%)$

$2962(86 \%)$

$256(7.4 \%)$

$228(6.6 \%)$

$2618(76 \%)$

$251(7.3 \%)$

$577(16.7 \%)$

$445(13 \%)$

3001 (87\%)

668 (19.4\%)

$2778(80.6 \%)$

$1419(41.2 \%)$

$2027(58.8 \%)$

$2432(70.6 \%)$

$1014(29.4 \%)$

$22,760(80 \%)$

686 (20\%)

595 (17.3\%)

999 (29\%)

830 (24\%)

$1022(29.7 \%)$

1311 (38\%)

1267 (36.8\%)

868 (25.2\%)

$1160(40.7 \%)$ 
Table 2 Descriptive characteristics of the respondents in Ethiopia, 2016 ( $N=3446)$ (Continued)

\begin{tabular}{lc}
\hline Variable & weighted frequency (\%) \\
\hline $2-3$ years & $922(32.4 \%)$ \\
Above3 years & $765(26.9 \%)$ \\
Place of delivery & $2837(82.3 \%)$ \\
Home & $609(17.7 \%)$ \\
Health facility & \\
Child characteristics & $1803(52.3 \%)$ \\
sex & $1643(47.7 \%)$ \\
Male & \\
Female & $3404(98.8 \%)$ \\
Birth type & $42(1.2 \%)$ \\
Single & \\
Multiple & $1023(29.7 \%)$ \\
ANC & $2423(70.3 \%)$ \\
Yes & \\
No & \\
\hline
\end{tabular}

cluster (cluster with higher under-five mortality) the odds of under-five mortality is 1.49 times compared to those from a lower-risk cluster. Moreover, the Loglikelihood ratio test was significant $\left(X^{2}\right.$ value $=4.63, P$ value $=0.0157)$. These all informed us to choose a mixed-effect logistic regression model (GLMM) over the basic model (Table 4 ).

\section{Fixed effects analysis}

Determinants of under-five mortality in the high-risk regions of Ethiopia were analyzed using a mixed-effect logistic regression model. Variables with a $p$-value $<0.2$ in the bivariable analysis were eligible for the multivariable analysis. In the multivariable analysis, parity, preceding birth interval, birth type, and ANC visit were significant determinants of under-five mortality. The odds of under-five mortality was 3.66 (AOR $=3.66$ : $95 \% \mathrm{CI} ; 1.55$, 8.68) times higher among mothers with parity of greater than six compared with those mothers having children of three and less in the family. Mothers with preceding birth intervals of two to 3 years and above 3 years had $43 \%(\mathrm{AOR}=0.57: 95 \% \mathrm{CI} ; 0.41,0.81)$ and $65 \%(\mathrm{AOR}=$ 0.35: $95 \% \mathrm{CI} ; 0.22$, 0.55) lower odds of under-five mortality as compared to mothers with preceding birth interval of fewer than 2 years. Being multiple births had $5.1(\mathrm{AOR}=5.1: 95 \% \mathrm{CI} ; 2.28,11.46)$ times higher odds of under-five mortality compared to a single birth. Moreover, there was a $63 \%(\mathrm{AOR}=0.2795 \% \mathrm{CI} ; 0.16,0.45)$ lower odds of under-five mortality among mothers with ANC visit during their last pregnancy compared to their counterparts (Table 5).

\section{Discussion}

The SDG is aimed at reducing preventable deaths of newborns and children under the age of five $[9,16]$. In this study, $7.46 \%(95 \% \mathrm{CI} ; 6.6,8.3 \%)$ of under-five children had died before celebrating their fifth birthday with a mortality rate of 74 per 1000 live birth. This finding was relatively higher than another study done in Ethiopia [10] and lower than other studies conducted in Ethiopia [2, 11]. The disparity may be attributed to variations in sample size and study setting, as the sample size in our study was relatively small compared to others. Besides, the discrepancy or the higher prevalence found in this study might be due to the poor socioeconomic status of the participants in these high-risk regions of Ethiopia [10].

The multivariable mixed-effects analysis showed that type of birth, ANC visit, preceding birth interval, and parity had significant associations with under-five mortality.

The odds of under-five mortality among multiple births were higher as compared to singleton births and this is consistent with different studies conducted in Ethiopia [2, 3, 11, 12]. This might be because multiple births can lead to growth retardation and prematurity, which are the main risk factor for under-five mortality [13]. In addition, being twins or triplets might result in under-nutrition because of inadequate breast milk as well as infections due to inappropriate formula feeding and feeding of cow's milk.

In the present study, under-five mortality increases as parity increases. This is consistent with a study carried out in Ethiopia [2] but in contrast to other studies [7, 
Table 3 The prevalence of under-five mortality in Ethiopia, $2016(N=3446)$

\begin{tabular}{|c|c|c|c|}
\hline Variables & Total & No of children died & Under-five mortality rate per 1000 \\
\hline \multicolumn{4}{|l|}{ Respondent current age } \\
\hline$<20$ & 154 & 14 & 91 \\
\hline $20-24$ & 793 & 56 & 71 \\
\hline $25-29$ & 1025 & 68 & 66 \\
\hline $30-34$ & 706 & 50 & 71 \\
\hline$>=35$ & 768 & 69 & 90 \\
\hline \multicolumn{4}{|l|}{ Religion } \\
\hline Muslim & 2962 & 222 & 75 \\
\hline Orthodox & 256 & 16 & 62 \\
\hline Others & 228 & 19 & 83 \\
\hline \multicolumn{4}{|l|}{ Sex } \\
\hline Male & 1803 & 137 & 76 \\
\hline Female & 1643 & 120 & 73 \\
\hline \multicolumn{4}{|l|}{ ANC } \\
\hline Yes & 1023 & 27 & 26 \\
\hline No & 2423 & 230 & 95 \\
\hline \multicolumn{4}{|l|}{ Birth type } \\
\hline Single & 3404 & 246 & 72 \\
\hline Multiple & 42 & 11 & 262 \\
\hline \multicolumn{4}{|l|}{ Mother education } \\
\hline No education & 2760 & 214 & 77 \\
\hline Primary and above & 686 & 43 & 63 \\
\hline \multicolumn{4}{|l|}{ Birth order } \\
\hline $1 s t$ & 595 & 57 & 96 \\
\hline $2-3$ & 999 & 60 & 60 \\
\hline 4th and above & 1852 & 140 & 75 \\
\hline \multicolumn{4}{|l|}{ Parity } \\
\hline $1-3$ & 1311 & 86 & 66 \\
\hline $4-6$ & 1267 & 85 & 67 \\
\hline$>6$ & 868 & 86 & 99 \\
\hline \multicolumn{4}{|l|}{ Wealth index } \\
\hline Poor & 2618 & 212 & 81 \\
\hline Middle & 251 & 14 & 56 \\
\hline Rich & 577 & 31 & 54 \\
\hline \multicolumn{4}{|l|}{ Residency } \\
\hline Urban & 445 & 21 & 47 \\
\hline Rural & 3001 & 236 & 79 \\
\hline \multicolumn{4}{|l|}{ Place of delivery } \\
\hline Home & 2837 & 223 & 79 \\
\hline Health facility & 609 & 34 & 56 \\
\hline \multicolumn{4}{|l|}{ Source water } \\
\hline Pipe & 668 & 40 & 60 \\
\hline Other & 2778 & 217 & 78 \\
\hline \multicolumn{4}{|l|}{ Toilet facility } \\
\hline Yes & 1419 & 96 & 68 \\
\hline No & 2027 & 161 & 79 \\
\hline \multicolumn{4}{|l|}{ Regions } \\
\hline Afar & 1062 & 90 & 85 \\
\hline Somali & 1505 & 103 & 68 \\
\hline Benishangul-Gumuz & 879 & 64 & 73 \\
\hline
\end{tabular}


Table 4 Model comparison and fitness for the assessment of determinants of under-five mortality

\begin{tabular}{lll}
\hline Model comparison & The standard logistic regression model & Mixed effect logistic regression model \\
\hline Log-likelihood & -668.0 & -667.29 \\
Deviance & 1336 & 1334.58 \\
Intraclass correlation(ICC) and median odds ratio(MOR) of the mixed effect model (Final model) & \\
ICC & 0.14 \\
MOR & 1.49 \\
\hline
\end{tabular}

Table 5 Multivariable mixed effect analysis for assessing the determinants of under-five mortality in high-risk regions of Ethiopia, 2016

\begin{tabular}{|c|c|c|}
\hline Variables & COR $(95 \% \mathrm{Cl})$ & AOR $(95 \% \mathrm{Cl})$ \\
\hline \multicolumn{3}{|l|}{ Parity } \\
\hline $1-3$ & 1 & 1 \\
\hline $4-6$ & $1.01(0.73,1.38)$ & $1.72(0.99,2.99)$ \\
\hline$>6$ & $1.59(1.15,2.19)$ & $3.66(1.55,8.67)$ \\
\hline \multicolumn{3}{|l|}{ Wealth status } \\
\hline Poor & 1 & 1 \\
\hline Middle & $0.67(0.38,1.19)$ & $0.88(0.45,1.7)$ \\
\hline Rich & $0.63(0.42,0.96)$ & $0.67(0.35,1.3)$ \\
\hline \multicolumn{3}{|l|}{ Birth interval } \\
\hline $2-3$ years & $0.55(0.39,0.77)$ & $0.57(0.41,0.81)$ \\
\hline above 3 years & $0.32(0.205,0.49)$ & $0.35(0.22,0.55)$ \\
\hline \multicolumn{3}{|l|}{ Residence } \\
\hline Urban & 1 & 1 \\
\hline Rural & $1.71(1.04,2.8)$ & $1.15(0.52,2.56)$ \\
\hline \multicolumn{3}{|l|}{ Type of birth } \\
\hline Single & 1 & 1 \\
\hline multiple & $4.42(2.15,9.06)$ & $5.12(2.28,11.46)$ \\
\hline \multicolumn{3}{|c|}{ Source of drinking water } \\
\hline Protected & 1 & 1 \\
\hline Unprotected & $1.37(0.94,1.99)$ & $1.06(0.67,1.69)$ \\
\hline \multicolumn{3}{|c|}{ Sex of household head } \\
\hline Male & 1 & 1 \\
\hline Female & $0.77(0.57,1.05)$ & $0.84(0.58,1.2)$ \\
\hline \multicolumn{3}{|l|}{ Place of delivery } \\
\hline Home & 1 & 1 \\
\hline health facility & $0.69(0.47,1.02)$ & $1.07(0.63,1.8)$ \\
\hline \multicolumn{3}{|l|}{ Mother education } \\
\hline No education & 1 & 1 \\
\hline primary and above & $0.8(0.57,1.14)$ & $1.37(0.85,2.22)$ \\
\hline \multicolumn{3}{|l|}{ ANC visit } \\
\hline No & 1 & 1 \\
\hline Yes & $0.25(0.17,0.38)$ & $0.27(0.16,0.45)$ \\
\hline
\end{tabular}

14]. This might be because mothers with higher parity might be busy caring for many children in the family and may give limited attention to the health of their last child. Besides, mothers with higher parity had enough number of children so they might be careless in seeking appropriate care from the health facility for this child [17]. Additionally, in this study, there were higher odds of under-five mortality among children born from mothers with a previous birth interval of fewer than 2 years. This finding is in line with other studies [2-4]. This might be as a result of short birth interval might lead to premature birth and limited family resources because of the increased number of children in the family $[11,16,19]$. Also, mothers with short preceding birth interval might be exposed to malnutrition and this, in turn, affect her child in getting appropriate nutrients from the mother and might expose the child to malnutrition and infections, which finally ends up with death.

Moreover, children of women who had ANC visits during pregnancy had a lower risk of mortality relative to those of mothers with no ANC visits. This finding is consistent with the study conducted in Ethiopia [4] but in contrast with other studies $[3,15]$. This might be because mothers with appropriate utilization of maternal health services such as ANC visits might induce appropriate information for the mother regarding the health of the newborn and appropriate feeding practices to prevent infections [18]. In addition, mothers with ANC visits might have a probability of taking postnatal care that is crucial for searching for childhood health problems and taking appropriate intervention timely.

\section{Strength and limitation of the study}

This study was based on nationally representative data with a large sample size. Besides, it was based on an appropriate statistical approach (mixed-effect analysis) to accommodate the community or cluster level variability of under-five mortality. Moreover, since it is based on the national survey data the study has the potential to give insight for policy-makers and program planners to design appropriate intervention strategies both at national and regional levels. However, this study had 
limitations in that the EDHS is mostly based on respondents' self-report and might have the possibility of recall bias. Besides, since the study was based on the information available in the EDHS data, there might be residual confounding factors.

\section{Conclusion}

In the high-risk region of Ethiopia the prevalence of under-five mortality is high. Under-five mortality in these regions was significantly associated with preceding birth interval, type of birth, parity, and ANC visits. Thus, special emphasis should be given to those mothers with no ANC visit, preceding birth interval of fewer than 2 years, mothers with higher parity, and multiple births.

\section{Abbreviations}

ANC: Antenatal care; Cl: Confidence interval; EA: Enumeration area; EDHS: Ethiopian demographic health survey; GLMM: Generalized linear mixed model; ICC: Intraclass Correlation Coefficient; LLR: Likelihood ratio; MDG: Millennium development goal; SDG: Sustainable development goals; WHO: World Health Organization

\section{Acknowledgments}

We greatly acknowledge MEASURE DHS for granting access to the Ethiopia Demographic and Health Surveys data.

\section{Authors' contributions}

GAT, MGW ABT conceived the study. GAT, MGW, ABT analyzed the data. GAT, MGW, ABT drafted the manuscript and reviewed the article. GAT, MGW, ABT extensively reviewed the article. All authors read and approved the final manuscript.

\section{Funding}

No funding was obtained for this study.

\section{Availability of data and materials}

The data set is available online and any one can access it from www. measuredhs.com.

\section{Declarations}

\section{Ethics approval and consent to participate}

Since the study was a secondary data analysis of publically available survey data from the MEASURE DHS program, ethical approval and participant consent were not necessary. We requested DHS Program and permission was granted to download and use the data from http://www.dhsprogram. com. There are no names of individuals or household addresses in the data files.

\section{Consent for publication}

Not applicable.

\section{Competing interests}

Authors declare that they have no conflict of interest

\section{Author details}

'Department of Human Anatomy, College of Medicine and Health Science, School of Medicine, University of Gondar, Gondar, Ethiopia. ${ }^{2}$ Department of Epidemiology and Biostatistics, Institute of Public Health, College of Medicine and Health Sciences, University of Gondar, Gondar, Ethiopia.
Received: 8 September 2020 Accepted: 11 April 2021

Published online: 23 April 2021

\section{References}

1. Zewudie AT, Gelagay AA, Enyew EF. Determinants of under-five child mortality in Ethiopia: analysis using Ethiopian demographic health survey, 2016. Int J Pediatr. 2020;2020.

2. Gebretsadik S, Gabreyohannes E. Determinants of under-five mortality in high mortality regions of Ethiopia: an analysis of the 2011 Ethiopia demographic and health survey data. Int J Popul Res. 2016; [cited 2020 Apr 9]. Available from: https://www.hindawi.com/journals/ijpr/2016/1602761/.

3. Nations U. Reducing child mortality - the challenges in Africa: United Nations. Available from: https://www.un.org/en/chronicle/article/reducingchild-mortality-challenges-africa

4. Y G, S B. Survival analysis of under-five mortality of children and its associated risk factors in Ethiopia. J Biosens Bioelectron. 2016;7(3) [cited 2020 Apr 9]. Available from: https://www.omicsonline.org/open-access/ survival-analysis-of-underfive-mortality-of-children-and-its-associatedrisk-fa ctors-in-ethiopia-2155-6210-1000213.php?aid=78670.

5. Bryce J, Victora C, Berman P, Lawn J, Mason E, Starrs A. Fulfilling the Health Agenda for Women and Children. 2014.

6. Central Statistical Agency (CSA) [Ethiopia] and ICF. Ethiopia demographic and health survey 2016. Addis Ababa, Ethiopia, and Rockville: CSA and ICF; 2016.

7. 08Chapter8.pdf. [cited 2020 Apr 13]. Available from: https://dhsprogram. com/pubs/pdf/FR123/08Chapter8.pdf.

8. Ettarh R, Kimani J. Determinants of under five mortality in rural and urban Kenya. Rural Remote Health. 2012;12:1812.

9. WHO | Global Health Observatory (GHO) data. WHO. [cited 2020 Apr 9]. Available from: http://www.who.int/gho/en/

10. Fikru C, Getnet M, Shaweno T. Proximate determinants of under-five mortality in Ethiopia: using 2016 nationwide survey data. Pediatr Health Med Ther. 2019; [cited 2020 Apr 9]. Available from: https://www.dovepress. com/proximate-determinants-of-under-five-mortality-in-ethiopia-using-201 6\%2D\%2Dpeer-reviewed-article-PHMT.

11. Asena T, Shamenna A, Disassa A, Wang Q-W. Variations in under-five child mortality among regional states of Ethiopia: a multi-level modelling approach; 2016.

12. Aheto JMK. Predictive model and determinants of under-five child mortality: evidence from the 2014 Ghana demographic and health survey. BMC Public Health. 2019;19(1):64. https://doi.org/10.1186/s12889-019-6390-4.

13. Berelie Y, Yismaw L, Tesfa E, Alene M. Risk factors for under-five mortality in Ethiopia: evidence from the 2016 Ethiopian demographic and health survey. S Afr J Child Health. 2019;13(3):137-140-140. https://doi.org/10.7196/SAJCH.2019. v13i3.1645.

14. Mehretie Adinew Y, Feleke SA, Mengesha ZB, Workie SB. Childhood mortality: trends and determinants in Ethiopia from 1990 to 2015-a systematic review. Adv Public Health. 2017. Available from: https://www.hindawi.com/journals/a ph/2017/7479295/:1-10. https://doi.org/10.1155/2017/7479295.

15. Mekonnen Y, Ayalew T, Dejene A. Estimation of child mortality in Addis Ababa. Ethiop J Health Dev. 1995;9(3).

16. Woldeamanuel BT. Socioeconomic, demographic, and environmental determinants of under-5 mortality in Ethiopia: evidence from Ethiopian demographic and health survey, 2016. Child Dev Res. 2019; Available from: https://www.hindawi.com/journals/cdr/2019/1073782/.

17. Deribew A, Tessema F, Girma B. Determinants of under-five mortality in Gilgel gibe field research center, Southwest Ethiopia. Ethiop J Health Dev. 2007;21(2):117-24.

18. Mutunga CJ. Environmental determinants of child mortality in Kenya. In: McGillivray M, Dutta I, Lawson D, editors. Health inequality and development. London: Palgrave Macmillan UK; 2011. p. 89-110. [cited 2020 Apr 9]. (studies in development economics and policy). Available from: https://doi.org/10.1057/9780230304673_5.

19. Haroun HM, Mahfouz MS, Ibrahim KH. Level and determinants of infant and under-five mortality in wad-medani town, Sudan. J Fam Community Med. 2007;14(2):65-9.

\section{Publisher's Note}

Springer Nature remains neutral with regard to jurisdictional claims in published maps and institutional affiliations. 